\title{
IMPACTOS E INJUSTIÇAS AMBIENTAIS: SIGNIFICAÇÕES DE ATORES QUE CONSTITUEM UM CONFLITO SOCIOAMBIENTAL
}

\author{
Pândela Figueiredo Santos ${ }^{1}$ \\ Amanda Machado Dias ${ }^{2}$ \\ Angélica Cosenza ${ }^{3}$ \\ Juliana Amorim Fonseca ${ }^{4}$ \\ Michele Alice da Silva ${ }^{5}$
}

\section{Resumo}

O presente estudo tem como objetivo analisar possíveis significações existentes em torno de um conflito socioambiental instaurado a partir da construção de uma rodovia, no município de Juiz de Fora, MG. Objetiva, também, refletir sobre as implicações de conflitos socioambientais à educação ambiental e à relação comunidade-escola. A metodologia da pesquisa apoia-se na análise de conteúdo proposta por Laurence Bardin. A pesquisa se utilizou de entrevistas realizadas com alguns sujeitos que tomam parte do movimento Diga não à BR440, em Juiz de Fora, MG. A análise de tais entrevistas consistiu de pré-análise, exploração do material e interpretação dos resultados. Observamos diferentes sentidos acerca de impactos que sustentam posicionamentos contrários e favoráveis à obra. Tais sentidos potencializam, neste trabalho, reflexões e práticas sobre a necessidade de articulação entre Educação Ambiental e Justiça Ambiental em uma escola que se encontra no entorno do empreendimento.

Palavras-chave: Educação ambiental. Comunidade-escola. Injustiças socioambientais.

\section{ENVIRONMENTAL IMPACTS AND INJUSTICES: MEANINGS FROM ACTORS WHO ARE INVOLVED IN A SOCIO-ENVIRONMENTAL CONFLICT}

\begin{abstract}
This study aims to analyze possible existing meanings concerning a socioenvironmental conflict initiated with the construction of a highway in the city of Juiz de Fora, MG. It also aims to reflect on the implications of socio-environmental conflicts for environmental education and for the community-school relationship. The research methodology relies on content analysis, proposed by Laurence Bardin. Interviews with some individuals who take part in the movement Say No to BR440 in Juiz de Fora, MG, are used in the survey. The analysis of these interviews consisted of pre-analysis, material exploration and results interpretation. We have observed different meanings about impacts which hold contrary and favorable positions about the construction. Such views boost reflections and practices, in this work, on the need for coordination between Environmental Education and Environmental Justice in a school which is located in the vicinity of the enterprise.
\end{abstract}

\footnotetext{
${ }^{1}$ Licenciada em Ciências Biológicas, Universidade Federal de Juiz de Fora (UFJF).

${ }^{2}$ Licenciada em Ciências Biológicas, Universidade Federal de Juiz de Fora (UFJF).

${ }^{3}$ Prof $^{\mathrm{a}}$. Dr ${ }^{\mathrm{a}}$. Faculdade de Educação, Universidade Federal de Juiz de Fora (UFJF).

${ }^{4}$ Professora Ciências Naturais no Ensino Básico.

${ }^{5}$ Licenciada em Ciências Biológicas, Universidade Federal de Juiz de Fora (UFJF).
} 
Keywords: Environmental education, community-school, socio-environmental injustices.

\section{IMPACTOS E INJUSTICIAS AMBIENTALES: SIGNIFICACIONES DE ACTORES QUE CONSTITUYEN UN CONFLICTO SOCIO-AMBIENTAL}

\section{Resumen}

Este estudio tiene como objetivo analizar los posibles significados existentes en torno a un conflicto socio-ambiental que se inició con la construcción de una carretera en la ciudad de Juiz de Fora, MG. También, tiene como objetivo reflexionar sobre las consecuencias de los conflictos ambientales para la educación ambiental y la relación escuela-comunidad. La metodología de investigación se basa en el análisis de contenido propuesto por Laurence Bardin. La investigación utilizó entrevistas con algunos individuos que toman parte en el movimiento Di No a la BR440, en Juiz de Fora, MG. El análisis de estas entrevistas consistió en pre-análisis, exploración de material y la interpretación de los resultados. Observamos a los diferentes sentidos sobre los impactos que mantienen posiciones contrarias y favorables al desarrollo de la carretera. Tales sentidos potencian, en este trabajo, reflexiones y prácticas sobre la necesidad de coordinación entre la Educación Ambiental y la Justicia Ambiental en una escuela que está alrededor de la empresa.

Palabras-clave: Educación Ambiental. Comunidad-escuela. Injusticia socio-ambiental.

\section{Introdução}

Partindo de um contexto que envolve processos relacionados a problemas e injustiças socioambientais decorrentes da construção de uma rodovia (denominada BR 440) dentro do município de Juiz de Fora - MG, o presente estudo tem como objetivo analisar sentidos acerca desses processos envolvidos em um conflito socioambiental (Movimento Diga Não à BR440), que se estabelece a partir da construção da rodovia. Além disso, também objetivamos refletir sobre as implicações de conflitos socioambientais à educação ambiental e à relação comunidade-escola. Tal estudo se desenvolveu como parte preliminar no âmbito de dois projetos de pesquisa do Grupo de Educação Ambiental da Faculdade de Educação da UFJF (GEA) ${ }^{6}$.

Nas últimas décadas, assistimos a diversas impactações ao meio ambiente, os quais vêm afetando a vida humana e a não humana de forma considerável, em um contexto de crise e de conflitos socioambientais cada vez mais explícitos. Nesse contexto, violações de direitos humanos constituem uma dura realidade daqueles que vivem nas "zonas de sacrifício" (ACSERALD; MELLO, 2009) da expansão capitalista, que leva a uma crescente expropriação da terra e dos meios de sobrevivência de comunidades cada vez menos tradicionais e cada vez mais socioambientalmente vulneráveis.

\footnotetext{
${ }^{6}$ Tais projetos são denominados Problemas e injustiças ambientais locais nas construções discursivas de professores e professoras e Controvérsias socioambientais no contexto escolar da construção de sentidos sobre injustiças ambientais (respectivamente, Editais Propesq/UFJF, 2015, 2014). O foco de tais projetos está em analisar: 1) discursos textuais produzidos por docentes de uma escola pública local e 2) discursos orais de estudantes do ensino fundamental acerca de processos de injustiças e conflitos socioambientais de suas comunidades. Em ambos os projetos, concluídos em 2016, o principal elemento disparador das construções discursivas a serem analisadas é o conflito socioambiental da BR440.
} 
Em um primeiro momento, a discussão ambiental se voltou à conservação da natureza e ao direito das gerações futuras a um ambiente limpo e sustentável. Mais recentemente, a temática ambiental assume, também, uma dimensão político-ideológica, articulando a questão ambiental à social, dando, por exemplo, mais evidência a processos de injustiças ambientais e conflitos socioambientais (HALUZA-DELAY, 2013).

Nesse sentido, as preocupações residem nas comunidades que vivenciam efeitos da desigual distribuição de bens e serviços ambientais, já que o acesso à água tratada, saneamento básico, direitos a áreas verdes e de lazer, dentre outros, são atributos ambientais que se distribuem de maneira desigual nos diferentes grupos sociais. Essas preocupações estão no cerne do movimento por justiça ambiental que, a partir de uma articulação entre movimentos de caráter social, territorial, ambiental e de direitos, nasceu nos EUA, na década de 80, objetivando que o ambiente tomasse parte da cultura de direitos.

Para designar um fenômeno de imposição desproporcional de riscos socioambientais às populações menos dotadas de recursos financeiros e políticos, o movimento consagrou o termo injustiça ambiental. A meta do movimento consiste na reivindicação por justiça ambiental, compreendida como o tratamento justo e o envolvimento pleno dos grupos sociais, nas decisões sobre o acesso, a ocupação e o uso dos recursos ambientais em seus territórios (SCHLOSBERG, 2007; BULLARD, 2004).

Muitos processos de injustiças ambientais e de clara violação a direitos humanos, quando materializados em lutas comunitárias e populares, podem expressar-se em conflitos socioambientais. De acordo com Acserald e Mello (2009) os conflitos socioambientais ocorrem quando os sujeitos pertencentes aos grupos sociais com modos diferentes de apropriação, uso e significado do território, reagem diante dos riscos a que estão submetidos.

Pela nítida relação entre equilíbrio ecológico, direitos humanos e (in)justiça ambiental, os conflitos socioambientais se tornam cada vez mais presentes, envolvendo controvérsias entre diferentes setores e protagonistas sociais. Levinson (2006) considera que questões controversas são aquelas que, comumente, dividem a sociedade, e para as quais grupos significativos oferecem explicações e soluções conflitantes.

Diante dessas controvérsias e conflitos socioambientais, o campo da Educação Ambiental (EA) vem sendo chamado a responder a processos participativos para envolvimento pleno dos grupos sociais nas decisões sobre o acesso, a ocupação e o uso dos recursos ambientais em suas comunidades (COSENZA; KASSIADOU; SÁNCHEZ,2014).

A EA tem um papel importante no processo de empoderamento comunitário e tomada de decisões, sendo um dos meios educativos pelo qual se pode articular as dimensões ambiental e social, problematizar a realidade socioambiental e as raízes da crise civilizatória. Tal perspectiva caracteriza uma educação ambiental denominada de crítica ou transformadora (LOUREIRO, 2004). Porém, segundo Cosenza e Martins (2012) e Haluza Delay (2013), o campo da EA ainda reflete pouco sobre temáticas relativas às desigualdades, às injustiças e aos conflitos socioambientais.

A supressão da reflexão sobre justiça ambiental e conflitos socioambientais na construção do saber ambiental produz um esvaziamento político que reforça a dimensão ecológica da questão ambiental, em detrimento das dimensões políticas, éticas e econômicas (COSENZA; KASSIADOU; SÁNCHEZ,2014). Tal supressão opera, no âmbito da escola, a opacidade curricular de questões socialmente vivas. Ora, fica 
estabelecida uma contradição, já que, concomitante a essa omissão, os filhos e filhas de famílias tão desiguais têm garantido o acesso à escola, mais do que nunca antes, tensionando as políticas públicas e as práticas pedagógicas, principalmente, em espaços de acirrados problemas e conflitos socioambientais territoriais. Arroyo (2011) alerta para o risco de secundarizar as vivências mais radicais dos sujeitos em situações de vulnerabilidade social, e defende a importância do reconhecimento de tais sujeitos e suas duras realidades nos currículos e nas práticas educativas escolares.

A partir dos sujeitos e dos grupos sociais em situação de vulnerabilidade socioambiental, é possível dar visibilidade às realidades vivenciadas por eles, o que possibilita uma melhor compreensão da sociedade e de suas contradições. Esse é um dos propósitos da EA que se pretende crítica, em sua defesa da articulação entre formação cidadã, justiça social e participação comunitária (LOUREIRO; LAYRARGUES, 2013).

Diante de tais processos agudos de degradações e desigualdades socioambientais, o presente estudo se justifica por complexificar o debate sobre processos de injustiças ambientais e lutas comunitárias em sua interface com a Educação Ambiental na escola. As interfaces propostas podem contribuir para ampliar as discussões que são, ainda, incipientes no campo da EA.

\section{Referencial Teórico-Metodológico}

Como dito anteriormente, apresentamos, aqui, parte inicial de dois projetos que se entrecruzaram e que visaram à didatização de processos de injustiças ambientais locais e, a partir desta, à análise discursiva de significações de professores, professoras e estudantes em torno de tais processos. Neste artigo procuramos discutir sentidos acerca da caracterização do conflito socioambiental pelos sujeitos que tomam parte dele, bem como a implicação desses sentidos contextualizados na comunidade-escola.

Tal investigação iniciou-se em agosto de 2014, com um estudo bibliográfico de temáticas referentes às relações entre justiça ambiental, conflitos ambientais e educação ambiental. Durante a primeira etapa, também realizamos um levantamento de processos de conflitos socioambientais locais na cidade de Juiz de Fora, MG. Dentre tais processos, aquele escolhido pelo grupo de pesquisa foi o movimento Diga não à $B R$ 440 por sua atividade em questões socioambientais envolvendo o direito à cidade, à mobilidade urbana, à transparência de uso de recursos financeiros públicos, ao saneamento básico, à conservação de recursos naturais e à resolução de problemas comunitários.

A partir dessa escolha, um roteiro para entrevistas com os atores que tomam parte do movimento foi construído, a partir de temáticas relevantes ao reconhecimento do conflito local delimitado. Segundo Bogdan e Biklen (1994), a entrevista do tipo etnográfico é uma ferramenta utilizada para recolher dados descritivos na linguagem dos sujeitos entrevistados. Isso permite ao investigador identificar as interpretações dos sujeitos sobre determinados aspectos. A intenção do grupo foi conduzir entrevistas, sem perguntas rígidas, priorizando a voz dos sujeitos. As entrevistas foram videogravadas e, posteriormente, foram transcritas e analisadas. Os sujeitos da investigação foram listados no Quadro 1.

\section{\begin{tabular}{l|l} 
Entrevistados & Função \\
\hline & -
\end{tabular}}

1- Marta

Moradora. Residente há 14 anos na comunidade

${ }^{7}$ Nomes fictícios. 


\begin{tabular}{|ll|l|}
\hline & & atingida. \\
\hline $2-$ & Teresa & Advogada, com experiência em causas ambientais. \\
\hline $3-$ & Fabiano & Engenheiro ambiental, professor e ambientalista. \\
\hline $4-$ & José Augusto & Engenheiro e empresário do ramo imobiliário. \\
\hline $5-$ & André & Servidor público e morador da região. \\
\hline $6-$ & Carlos & Secretário de governo da prefeitura \\
\hline $7-$ & Altair & Arquiteto e ambientalista. \\
\hline
\end{tabular}

Quadro 1 - Sujeitos entrevistados e algumas características

Fonte: Criado pelos autores

$\mathrm{Na}$ análise das entrevistas, utilizamos como referencial a análise de conteúdo proposta por Bardin (2011). De acordo com essa autora, a análise deve ser realizada em três etapas, quais sejam: a pré-análise; a exploração do material e a análise e interpretação dos resultados.

No momento da pré-análise, realizamos a transcrição e leitura flutuante das entrevistas, de acordo com os objetivos traçados. Na fase de exploração do material, a transcrição das entrevistas foi recortada em temas para que fosse realizado o processo de codificação, com o intuito de chegarmos a uma correspondência entre a presença do tema e os significados inferidos pelos sujeitos.

A fase de análise e interpretação dos resultados caracterizou-se pela tentativa de interpretação dos significados atribuídos pelos sujeitos de pesquisa a cada tema delimitado na etapa anterior. Para isto, consideramos os enunciados dos sujeitos, buscando complementaridades, refutações, confirmações entre trechos específicos dentro dos segmentos selecionados, trechos estes que tratavam dos temas: envolvimento pessoal dos entrevistados no conflito, suas definições acerca dos processos de impactação socioambiental da rodovia, suas significações acerca de processos de (in)justiça ambiental, significações sobre demais atores e posições antagônicas que constituem o conflito socioambiental da BR440.

Buscamos produzir um mapeamento interpretativo para nossas questões de interesse. Assim, este estudo foi marcado por um movimento interpretativo, interessado em produzir uma elaboração analítica sobre o modo particular como os sujeitos denotavam sentidos para o conflito socioambiental da BR440.

Dando prosseguimento à investigação e, para que pudéssemos entender melhor as relações entre conflitos, injustiças e a comunidade e, ainda, entender como a obra relaciona-se aos modos de vida de alunos e alunas que dela sofrem influência, escolhemos uma escola que se encontra em posição estratégica em relação à construção da BR440. Nas primeiras visitas à escola, trabalhamos com a observação participante (BOGDAN; BIKLEN,1994) do espaço escolar, onde buscamos caracterizar a comunidade escolar e a comunidade local. Também, buscamos analisar os projetos de educação ambiental realizados na escola, a fim de identificarmos pressupostos e características.

\subsection{O conflito socioambiental da Br440 a partir dos atores que dele participam}

O plano diretor, aprovado por lei municipal, é o instrumento básico da política de desenvolvimento e expansão urbana, além de ser parte integrante do processo de planejamento municipal. Conforme explica Furtado (2010), o plano diretor do município de Juiz de Fora, MG foi instituído pela lei $\mathrm{n}^{\circ} 9.811$, no ano de 2000; no parágrafo único do art. 38 do referido Plano, estava prevista a construção de uma via 
denominada São Pedro. Vale ressaltar que tal via já fazia parte do plano viário da Cidade Alta no final da década de 1980, e começou a ser construída em 1999.

Essa via teria como objetivo realizar a conexão local interbairros, sob a alegação de que algumas regiões da cidade apresentavam carências e deficiências nos seus sistemas viários de interligação, refletidas na má circulação viária municipal, especialmente na área central. Contudo, tal via foi federalizada, isto é, incluída no Plano Nacional Viário, por meio da lei $\mathrm{n}^{\circ} 11.482$ no ano de 2007 em seu artigo 12, passando, então, a ser de responsabilidade do Departamento Nacional de Infraestrutura de Transportes (DNIT) e a ser designada como BR-440 (BRASIL, 2007). Essa rodovia federal possuía, agora, o objetivo de ligar duas rodovias, a BR-040a BR-267 (VILARDI; VILARDI, 2012).

Segundo Carlos, a federalização teve relação com a necessidade de captar recursos federais pelo município:

Para que essa obra pudesse ser realizada com recursos do governo federal ela teve que ser federalizada. Ela deixou de ser do município e passou a ser do governo federal. E sendo do governo federal ela teria que ser uma rodovia porque rua, avenida é de responsabilidade do município. As rodovias são de responsabilidade do governo federal.

Altair também fala sobre o assunto:

A prefeitura, por falta de recursos, viu que precisava engendrar alguma questão político-econômica pra viabilizar essa obra. E aí, a parte jurídica achou dentro do grande incentivo que foi dado pela Presidente Dilma no primeiro mandato, o PAC, os vários PACs.

A construção da rodovia BR-440 dentro do município de Juiz de Fora foi iniciada, efetivamente, no ano de 2009. Em seu projeto estava prevista a construção de nove quilômetros de rodovia, que cortaria dezessete bairros da cidade. De acordo com Marta, "eles alegam, aí no caso, que a finalidade seria desafogar o trânsito do centro da cidade e desenvolver a região". Durante sua construção, a BR 440 não passou por licenciamento ambiental porque, segundo Macedo (2011) a Superintendência Regional de Meio Ambiente e Desenvolvimento Sustentável da Zona da Mata - SUPRAM - teria alegado que o porte ou o potencial poluidor da obra seria inferior ao necessário para sua realização.

Com a construção da rodovia, em 2010, nasceu o movimento Diga Não à $B R$ 440, que realizou várias ações judiciais, extrajudiciais, bem como ações de mobilização social contrárias à construção da obra, procurando dar visibilidade aos impactos gerados ao ambiente e aos moradores da região. Sob esse aspecto, nas palavras de Teresa:

Acontece o seguinte: aqui a gente "tava" lidando com a União. A obra era federal, não era uma obra municipal. Então, a união não vai ouvir a população de Juiz de Fora. A distância daqui pra lá, não só a distância física, é gigantesca! Não tem como um grupo social impedir uma obra federal, ainda mais em uma época de eleição.

Teresa revelou as dificuldades que afetaram o movimento. Sob esse aspecto, Fabiano traz novas dificuldades por parte de empreendedores locais: "Os loteadores querem, por questão de acharem que vão valorizar seus lotes, seus imóveis. O que eu acho que não vai valorizar [...] se esse negócio acontecer mesmo, e o fluxo de veículo, né? Poluição visual, acidente, sonora". Também na fala de Marta, posicionamentos contrários ao movimento advindos dos próprios moradores: "os moradores da região achavam que o movimento estava barrando o progresso do bairro". 
André explica o modo como a população vê a construção de uma BR em meio a um bairro com características residenciais e já consolidado:

Primeiro, foi vendido pra população uma ideia que essa obra, BR 440, traria desenvolvimento pra região. Então, isso foi uma manchete, né? Divulgado pela mídia. [...]. No primeiro momento, para o cidadão que não conhece os detalhes da obra, isso é um bom negócio. Mas o cidadão não conhece, vai alguém e fala que vai trazer desenvolvimento... Ótimo! Vai trazer desenvolvimento é bom! Só que, à medida que você conhece o projeto e explica pras pessoas, nas suas diversidades, as consequências nefastas do empreendimento, as pessoas mudam de opinião.

Para José Augusto esse tipo de empreendimento é um processo natural nas cidades em crescimento. Em suas palavras:

O que está acontecendo é o seguinte... De maneira geral tá acontecendo uma transformação nas cidades né? Muito mais evidente nas grandes metrópoles, mas também nas cidades de médio porte. Isso tem acontecido por uma série de fatores. Eu diria que as principais são a questão do aumento da ocupação urbana, da mobilidade urbana e das tecnologias. Isso coloca a questão ambiental um pouco na rota de colisão.

Em 2011, diante de várias denúncias de irregularidades, o Tribunal de Contas da União - TCU - pediu a paralisação das obras e a construtora responsável deveria realizar obras de segurança para amenizar as interferências danosas à população. Carlos comenta sobre o fato, deixando claro que a prefeitura estava a par dos problemas causados à população residente no local:

A obra foi paralisada por uma série de recursos na justiça. No Supremo Tribunal Federal, abriu-se um processo pra sindicância pra averiguar porque haviam suspeitas que o volume de recursos não era condizente com a obra propriamente dita. Que o processo licitatório não era um processo licitatório legítimo. A obra ficou paralisada lá vários anos [...]. Aquilo criou uma série de transtornos, principalmente para a comunidade.

Mesmo com as obras paralisadas, a cidade assistiu, entre 2010 e 2015, esforços da prefeitura para a retomada da mesma. Segundo Rocha (2010), a BR 440 injetaria tráfego pesado no centro de Juiz de Fora, pois, pelo trajeto previsto, seria necessário o trânsito por uma avenida movimentada, no centro da cidade. A rodovia também já apresenta, após duas licitações, valor bastante elevado, atingindo custo estimado de R\$ 107.988.001,69. Ainda, segundo Valente (2015), em dezembro de 2015 o DNIT liberou, para continuidade das obras, mais R $\$ 20,4$ milhões.

A respeito dos impactos gerados pela obra, os entrevistados se posicionam. Para Fabiano, as enchentes são o impacto principal dessa via. Em suas palavras:

Todo final e início de ano sabe? O canal que foi redimensionado não dá conta. A calha não dá conta, sabe? $\mathrm{E}$ todos esses erros grosseiros de engenharia civil resultam no retorno de água pras ruas, água que, no caso, sai do esgoto. Então, volta água pluvial com esgoto, tudo misturado. Então, começam a aparecer doenças que já estavam erradicadas como hepatite, leptospirose e outras mais, principalmente pela água, em contato com a água. Então muitas pessoas têm hortas na beira da via são Pedro e as verduras são vendidas na feira, então, contamina tudo! Como é que pode ter enchente na cidade alta? Quer dizer, é até piada, né? Enchente é geralmente em lugar baixo, onde a água desce e se acumula.

Teresa compactua dessa fala, e acrescenta:

Com as chuvas, o esgoto está voltando pra casa delas, tá saindo pelas pias, 
pelo vaso sanitário. As casas estão sendo inundadas a $1 \mathrm{~m}, 1,50 \mathrm{~m}$ de altura. $\mathrm{E}$, além disso, as doenças que estão gerando, né? Essas enchentes e algumas casas foram perdidas com as enchentes.

Ela menciona, ainda, problemas ligados a desapropriações "eles desapropriaram vários terrenos, várias áreas. Alguns eles não pagaram, outros eles pagaram valores irrisórios", e outros relacionados ao comprometimento da mobilidade urbana:

Então, vocês imaginam se a BR 440, como uma BR, cortando a nossa cidade, duas pessoas morreram, as tragédias estão acontecendo, ambientais, e o que o município diz: - Isso não é problema meu. Isso é do DNIT, é obra federal. [...] houve uma violação da lei de mobilidade urbana, gravíssima. Porque você tendo uma rodovia, né? Cortando bairros urbanos, você não tem como transpor essa rodovia, você não pode ir de um lugar para o outro. Por exemplo, cruzar uma rodovia não é como cruzar uma avenida. Ela tem aquelas defensas, aqueles blocos de cimento, os distanciamentos são enormes, as pistas. A pessoa está passando mal, ela vai ter duas alternativas: ou ela passa, faz o percurso da passarela ou ela tem um carro à disposição ou dinheiro pra pagar um táxi e levá-la a UPA, do outro lado da rua. Se você tem um filho que estuda no colégio $\mathrm{X}$ e você mora do outro lado da avenida onde está aquele colégio, você também vai ter que procurar a passarela mais próxima. Você só vai ter quatro passarelas!

Como podemos perceber, Teresa aponta problemas graves gerados pela construção de uma rodovia em meio a um bairro já constituído. Os pedestres serão os mais afetados, devido à pouca disponibilidade de passarelas.

A respeito da temática das impactações, Marta menciona, ainda, o trânsito pesado que cortará a região, o risco de óleo na pista e a possibilidade de acidentes: "Se ligarem isso, além do trânsito pesado, caminhões pesados passando aqui sem controle nenhum, vai ter óleo, vai ter acidente! Vamos ter um problema sério".

Por sua vez, Altair relata impactações que já acontecem na região:

Aconteceram acidentes, né? Com vítimas em função daquela obra que "tá" largada. Aconteceram estupros, né? Porque as pessoas passaram a usar o trecho, como a gente vê hoje, pra caminhada, pra andar de bicicleta. E aí, trecho abandonado, trecho sem iluminação...

Ao fazer esse relato, Altair ainda conta que, se houver a ligação entre as duas rodovias federais, BR 040 e BR 440, o número de atropelamentos só tende a aumentar.

A partir do ponto de vista da justiça ambiental, percebemos que empreendimentos como esse atingem, de forma desproporcional, os grupos sociais locais. As impactações serão mais sentidas pelos grupos mais vulneráveis socialmente, como já significaram Teresa, Fabiano, André e Altair. Diante dos impactos ambientais oriundos da construção da rodovia, e das falas dos sujeitos entrevistados, nos foi possível identificar, também, os sentidos conferidos por eles às injustiças ambientais recorrentes na região a partir da construção da BR440.

A desigual distribuição dos riscos ambientais nas diferentes classes sociais, fica clara na voz de Fabiano:

Então, começaram a obra nesse pedacinho, que nem é do meio. [...] É o pedacinho mais próximo da BR que era possível fazer a obra. [...] Então, esse trecho que foi feito, né? Realmente, é, foi um trecho mais fácil, vamos dizer assim, de ser feito, né? Que não tinha problema com o IBAMA, não tinha problema com a população, sabe? Porque lá embaixo no Vale do Ipê tem um pessoal de melhor poder financeiro, sabe? Então, a pressão em cima deles ia ser muito maior! [...] Aqui na Cidade Alta não! [...] O pessoal é de classe 
média, classe média-baixa. Então, acho que o poder de pressão é muito menor. Então, eles usaram essa estratégia: de fazer num lugar que tivesse menos resistência à obra.

André também fala a respeito da fragilidade da população perante as decisões do poder público, colocando em questão as relações de poder assimétricas existentes nas tomadas de decisões:

Daí você tem, de um lado, uma parte frágil da população, que não é organizada. E de outro lado, um poder econômico muito grande, traduzido pelo investimento dos empresários. Um poder público, que tem dinheiro, mas não tem um gerenciamento, uma preocupação social do investimento. Tanto o órgão federal, DNIT, quanto a prefeitura, jamais, jamais, em seis anos, se pronunciaram sobre as consequências de uma forma de minimizar os problemas que serão causados. Jamais, jamais houve esse diálogo, entendeu? Onde gera essa injustiça: uma luta de Davi contra Golias.

Segundo Schlosberg (2007) o enfoque distributivo da justiça ambiental apregoa a justa distribuição de bens e serviços ambientais para os indivíduos e comunidades. A fala de Fabiano deixa claro que há injustiça social na medida em que indivíduos pertencentes às classes menos favorecidas estariam mais vulneráveis aos riscos ambientais e com menor condição de resistência a eles. Já a fala de André traz significações quanto à falta de reconhecimento e de participação da população vítima dos impactos.

Além da dimensão distributiva, duas outras dimensões de injustiças ambientais vêm sendo discutidas por Schlosberg (2007): aquelas referentes à ausência de reconhecimento e ausência de participação. Para esse autor, o enfoque das injustiças não deve estar pautado apenas na má distribuição de bens e serviços para indivíduos e comunidades, e no privilégio de uns indivíduos/coletivos a despeito de outros. É necessário que os indivíduos e os grupos sociais sejam reconhecidos e sua participação seja fomentada diante de empreendimentos potencialmente impactantes.

Para Schlosberg (2007) pouco reconhecimento, tanto em nível individual, quanto coletivo, dificulta a participação política. Segundo ele, isso justifica uma demanda pelo empoderamento e por vozes comunitárias nas lutas frentes às injustiças ambientais.

Dessa forma, ao falar de justiça é necessário um entendimento mais ampliado, que associe as dimensões distributiva, de reconhecimento e participativa nos processos políticos, sociais e ambientais. Levar em conta as diferentes dimensões de injustiças abre caminho para melhor reconhecê-las e enfrentá-las.

Diante do exposto acerca das significações sobre impactações e injustiças que dizem respeito à construção da BR440, o quadro 2 sintetiza a análise dos discursos dos sujeitos estudados:

\begin{tabular}{|l|l|}
\hline Sujeitos & Posicionamentos \\
\hline \multirow{3}{*}{$\begin{array}{l}\text { Marta, Altair, Teresa, Fabiano e } \\
\text { André }\end{array}$} & $\begin{array}{l}\text { Integrantes do movimento Diga Não à BR 440, } \\
\text { sendo contrários à construção da rodovia BR440 e } \\
\text { à interligação da via existente à BR040. São } \\
\text { favoráveis ao uso e finalização da obra enquanto } \\
\text { uma via municipal de ligação interbairros. }\end{array}$ \\
\hline \multirow{2}{*}{ José Augusto } & $\begin{array}{l}\text { Também integrante do Movimento Diga Não à } \\
\text { BR440. Contrário à construção da rodovia, mas } \\
\text { favorável à interligação da BR 440 à BR 040. } \\
\text { Defende a utilização do espaço como via de } \\
\text { mobilidade urbana e local de valorização histórica. }\end{array}$ \\
\hline
\end{tabular}




\begin{tabular}{|l|l|}
\hline \multirow{3}{*}{ Carlos } & $\begin{array}{l}\text { Como representante da prefeitura, é a favor do } \\
\text { término da construção da BR 440, em todos os } \\
\text { seus requisitos. Defende a finalização da BR440 e } \\
\text { a sua ligação com a BR040 }\end{array}$ \\
\hline
\end{tabular}

Quadro 2 - Posicionamentos dos sujeitos em relação à construção da BR 440

Fonte: Criado pelos autores

$\mathrm{Na}$ seção seguinte, abordamos as peculiaridades da escola e as implicações da construção da BR440 no cotidiano da comunidade escolar e do entorno.

\subsection{A Escola da Lagoa ${ }^{8}$}

A Escola da Lagoa localiza-se na zona oeste da cidade de Juiz de Fora - MG, próxima à BR 040 no bairro São Pedro. Como mencionamos anteriormente, essa região passa por problemas socioambientais que acabam por afetar a população do entorno da escola, bem como os estudantes que tomam parte dela. Esses estudantes vêm, principalmente, de regiões próximas à escola e das zonas rurais que rodeiam a BR 040 . Desse modo, é inevitável que o trajeto de suas casas até a instituição seja afetado, caso a construção da rodovia se efetive.

Moradores e ambientalistas relataram vários problemas sobre a construção da BR 440 e seu impacto à escola. Altair traz, em sua fala:

[...] quando começou a obra atrás, a escola sofreu invasão de cobra, escorpião e não sei o quê [...]. Um monte de inseto. Claro! Vivia tudo ali na mata ali atrás, né? Mexeu, correu pra algum lugar. Então a escola começou a sofrer com isso. Depois, eles já tinham feito tanto boletim de ocorrência que "tavam" perdendo irmão de aluno, primo com atropelamento na 040. [...] Um menino que estudava lá tinha sido atropelado. Os meninos sentiram muito porque era primo desse, daquele... Embora seja aqui na cidade, do lado da BR 040, com umas características meio rurais ainda, e tal. Enfim, sentiram muito. Aí fizeram um boletim. E aí quando eu vi com o pessoal da polícia, o sargento, pô! De uns anos pra cá as mortes tinham sido muitas. Totalmente fora do que era padrão normal. Então isso era uma luz, um alerta de que o que aquilo poderia trazer. Além de ter aquela de lá, ia ter uma passando aqui do lado.

Em algumas falas, os alunos Julia e Altair ${ }^{3}$ também retratam o perigo da BR que separa suas casas da Escola.

Sábado quando tem aula a gente tem que pegar o ônibus e como eu moro perto da Débora a gente tem que pegar o ônibus e atravessar a BR só pra pegar o ônibus [...]. É perigoso... se a pessoa tiver mexendo no celular distraído o carro pode vir e te matar.

A BR tá sendo muito perigosa! Nesse mês já aconteceram três acidentes [...] um homem "tava" vindo de carro e o farol dele "tava" mais ou menos dando pra enxergar ai ele pegou e foi rolando até ali perto do Graal[...]também caiu um caminhão de galinha e outro de banana.

A escola possui uma dinâmica escolar diferenciada, para melhor atender as particularidades desses alunos. Para tanto, possui, por exemplo, horários de início e término das aulas articulados aos horários de ônibus. Sendo a oferta desses ônibus escassa na região. A escola também oferece almoço para os estudantes que fazem

\footnotetext{
${ }^{8}$ Nomes fictícios.
} 
atividades extraturno, como o reforço escolar, pois alguns deles moram em bairros distantes, de origem rural, e há dificuldade de mobilidade, necessitando que fiquem na escola um tempo maior.

A escola ocupa, aproximadamente, $500 \mathrm{~m}^{2}$, e conta com um total de 170 estudantes, distribuídos entre a Educação Infantil e o Ensino Fundamental, nos períodos da manhã e tarde. Em anos anteriores, esse número era de 232, podendo ter uma interferência devido à migração de estudantes para escolas do centro da cidade. De acordo com a coordenação da escola, existe flutuação de estudantes durante o ano, visto que alguns pais não possuem empregos fixos, são caseiros ou empregadas domésticas e, frequentemente, mudam de casa. Com isso, as crianças acabam tendo de sair da escola. Ocorre, também, o inverso: a entrada, na escola, de estudantes cujos pais trabalham nos condomínios rurais localizados nas proximidades.

Muitos estudantes retrataram não gostar de morar na zona rural, uma vez que, segundo eles, a região não possui muito movimento e, além disso, quando tem aula em sábado letivo o acesso à escola fica mais difícil do que o restante da semana.

Lucas $^{4}$ diz: "Eu vim morar aqui porque minha mãe separou do pai do meu irmão, ai ela conheceu o Márcio e veio morar aqui porque ele trabalha lá no sítio". Ana $J_{u ́ l i a}^{4}$ relata: "Eu morava aqui em cima, mas eu, minha irmã e minha mãe mudamos para o Morro da Glória. Meu padrasto continua aqui porque ele não gosta de cidade não, ele mora na fazendinha". Clovis ${ }^{4}$ diz: "Morar na fazendinha é ruim não tem movimento (...) mas dia de sábado lá é muito agitado". Mariana ${ }^{4}$ compartilha: "Eu gosto de morar lá, porque lá é bem sossegado, mas quando chega quinta, sexta, sábado e domingo lá é bem agitado porque tem festa de dia até a noite, mas eu não sou convida é festa de adulto" Walter ${ }^{4}$ menciona: "Eu moro pra lá da fazendinha ai eu vou de Kombi".

O bairro no qual a escola encontra-se inserida tem sido amplamente afetado pela expansão imobiliária. Nessa direção, foi providenciada a pavimentação da rua que dá acesso à escola, e que, também, serve de acesso ao condomínio. Os funcionários e professores contam que a redondeza da escola passou por grandes modificações a partir do início das obras de infraestrutura do condomínio. Como podemos observar na fala de alguns alunos que retratam o seu ambiente de moradia. Lucas": "Ah professora, eu não gosto daqui, porque aqui não tem muito movimento. Aqui é muito parado você não vê muita coisa [...]. Mas é bom porque minha família toda mora aqui também. Mariana ${ }^{4}$ "Lá na fazendinha é tudo de estrada de chão, mas tem poste e tem internet, menos na minha casa (...) algumas vezes falta energia lá".

Percebemos que as melhorias na escola devem-se ao fato de a mesma localizarse na entrada do condomínio de luxo. A revitalização não ocorreu devido à importância de investimentos na educação, bem como no reconhecimento geográfico, cultural e histórico da escola, mas, ao contrário, ocorreu para favorecer a promoção da região como um local atrativo para futuros moradores e investidores do ramo imobiliário e comercial. Os alunos reconhecem a chegada do condomínio como um modificador da paisagem que se diferenciou da realidade anteriormente vivida por eles. Walter "Lá no Alfaville é melhor porque parece coisa de rico, pode andar de patinete, bicicleta e a estrada é melhor que a nossa".

Luana $^{4}$ relata a tentativa da desapropriação da área lindeira do condomínio, ocorrida em um terreno de seus familiares, e mostra a relação de história e apego construídos pela sua avó, que se negou a vender o terreno. Também, podemos observar

\footnotetext{
${ }^{9}$ Todos os nomes são fictícios.
} 
em suas palavras a representação do empreendedor, que removeria os moradores mesmo contra suas vontades: “A casa do Rian, aquela perto do 'butiquim' da Ana, eles compraram e deram outra pra ele lá em Santos Dumont (bairro), ele continua estudando aqui 'fessora', ai desabaram a casa dele e não fizeram nada no lugar, não tem nada”. E complementa:

O pessoal do Alfaville ia destruir a minha casa junto com a do Gabriel "fessora", eles iam tirar pra fazer tipo um parque aquático ai depois eles resolveram não fazer (...) o terreiro da minha casa vai até a represa, ai eles conversaram com todo mundo que mora lá no terreiro de casa. Ai minha vó não queria, porque já tinha mais de uns 30 anos que ela morava aqui e ai eles falaram que ia fazer assim mesmo, ai depois falaram que não ia mais. Ai eles falaram que iam tirar a Escola e as casas, já pensou todo mundo sem casa, ia ser chato "fessora".

Desde 2005, a escola desenvolve alguns projetos ligados ao meio ambiente. O projeto Meio Ambiente tem como objetivo trabalhar a sustentabilidade, a fim de promover o bem-estar de seus estudantes).O trabalho visa promover a consciência para um consumo de maneira responsável, respeitando os limites e períodos de regeneração dos recursos naturais, evidenciando relações que sejam recíprocas entre a natureza e a sociedade, buscando implementar atitudes como, a redução da quantidade de lixo gerado, esperando que os alunos contribuam com a sustentabilidade do planeta (PROJETO, 2013).

Segundo a coordenadora pedagógica da escola, o projeto Meio Ambiente e Alimentação trata das questões relativas ao meio ambiente, associando-as à qualidade de vida. Ainda, o projeto Meio Ambiente: Alimentação, Esporte, Consumo e Sustentabilidade foi criado para aprofundar o projeto anterior, pois os professores e as professoras concluíram que poderiam refletir sobre a alimentação a partir de outras dimensões, visando, por exemplo, trabalhar as formas de coleta e destino do lixo, desperdício no uso da água, energia e alimentos, hábitos de cuidado com o corpo, finalidades da alimentação, publicidade e consumismo, relação entre esporte e sustentabilidade (PROJETO, 2014).

A análise de tais projetos demonstra que os mesmos possuem uma potencialidade na formação de sujeitos ecológicos com alguma perspectiva crítica, porém, não detectamos um trabalho educativo em EA ligado a temas geradores ambientais, representativos da realidade sócio-histórico-cultural vivida e a ser transformada (LOUREIRO; TORRES, 2014). Identificamos que os objetivos dos projetos analisados e supracitados não contemplam problemas socioambientais vivenciados por esses estudantes e por sua comunidade. Os projetos referem-se a uma educação ambiental pautada em temas mais globais do que locais, apresentando medidas de conservação da natureza.

\subsection{O Caso da BR 440: Implicações à Educação Ambiental e à Relação Comunidade-Escola}

A partir do contexto socioambiental da Escola da Lagoa e dos sentidos conferidos às temáticas das impactações ambientais e dos processos de injustiças ambientais pelos sujeitos que tomam parte do conflito socioambiental estudado, refletimos sobre a necessidade de trabalhos de EA nas escolas das comunidades impactadas pela obra. Tais trabalhos devem visar não só o ambiente natural como foco 
principal de estudo, mas, também, todas as relações socioculturais que permeiam tal conflito.

Tendo como fonte de pesquisa as análises das entrevistas podemos, através das diferentes visões dos protagonistas do conflito da BR440, compreender controvérsias, expressas pelos entrevistados, e, em grande parte, manifestas pela não construção da BR 440. Em contraposição à sua construção, está o posicionamento mantido pela Prefeitura de Juiz de Fora e por alguns empreendedores e pelo Departamento Nacional de Infraestrutura de Transportes (DNIT).

As falas dos sujeitos entrevistados, a partir da análise de conteúdo, revelam diferentes níveis de interação com os processos de injustiças ambientais provenientes da BR 440. Marta, por exemplo, traz, através de seu envolvimento direto como moradora, a dimensão da ausência de reconhecimento de seus direitos enquanto moradora e cidadã, por não ter sido chamada à participação no processo que culminou em desapropriação de parte de seu terreno. Isto, como dito, configura o sentido das injustiças por falta de reconhecimento e participação. Já Fabiano, estabelece o discurso sobre os processos de injustiça ambiental a partir da pluralização das visões das impactações e dos sentidos distributivos de injustiças. Teresa aponta diversas irregularidades jurídicas e suas consequências negativas para a cidade, no campo ambiental, social e financeiro. André relata as diferentes relações de poder existentes na construção da obra diante da qual, para ele, a população não tem seus direitos respeitados.

A presença da injustiça ambiental, na visão dos entrevistados, se faz fonte rica de formação na escola da Lagoa e no trabalho de Educação Ambiental que pode ser nela potencializado. A ótica dos sujeitos que tomam parte do conflito abre possibilidades formativas do lado de dentro da escola, uma vez que permite a caracterização e a visibilidade de processos socioambientais locais, agudos e vivos, de uma comunidade. Tais processos encontram-se, muitas vezes, invisibilizados e encobertos pelo discurso conservador de progresso e inclusão social.

$\mathrm{Na}$ escola, tais práticas podem ser incluídas no currículo, uma vez que as informações sobre as temáticas conflituosas ambientais locais permitem não só a conscientização do que é injusto, como propiciam subsídios para que professores e professoras de várias áreas trabalhem com a Educação Ambiental de forma interdisciplinar, ativa e crítica. Assim, os conflitos ambientais, segundo Cosenza e Martins (2013), podem ser tomados na escola como questões controversas, o que pode estimular o diálogo e o debate entre os estudantes, criando meios para um processo de ensino-aprendizagem coletivo e a formação de cidadãos conscientes e atuantes em suas comunidades.

A articulação entre Educação Ambiental e Justiça Ambiental, defendida por Haluza-Delay (2013) e Cosenza, Kassiadou e Sánchez (2014), favorece uma ampla visão de sustentabilidade e o desenvolvimento do sentido de justiça e cidadania por estudantes, professores e professoras. Nesse sentido, o ensinar e o aprender sobre o ambiental ganham uma implicação política e um dever ético para agir sobre o que se torna conhecido como injusto.

\section{Considerações Finais}

Os discursos dos sujeitos entrevistados trouxeram à tona o caráter controverso que permeia a construção da BR440, uma vez que seus argumentos e posicionamentos 
são antagônicos aos da Prefeitura de Juiz de Fora. Tais sujeitos problematizaram e complexificaram as impactações da rodovia e os processos de injustiças ambientais a eles subjacentes. Em suas falas, aparece a reivindicação pela distribuição justa de riscos, por reconhecimento e envolvimento pleno dos grupos sociais.

Dessa forma, o conflito socioambiental da BR 440 articula problemas, injustiças e lutas ambientais e nos permitirá novos caminhos em suas possibilidades didáticas no ambiente escolar. A enunciação de tais injustiças pelos sujeitos que as vivenciam permitirá dar visibilidade, na escola, às experiências de degradação, desigualdade e ativismos socioambientais locais. Acreditamos que isso pode resultar no fortalecimento das relações escola-comunidade, no envolvimento de estudantes em suas comunidades e em problemas que as atravessam.

Nesse contexto, compreender melhor a percepção dos estudantes, professores e professoras que tomam parte na comunidade da Escola da Lagoa, assim como desenvolver práticas pedagógicas que levem em consideração problemáticas locais, torna-se fundamental para que tais atores entendam melhor seu contexto socioambiental e sejam protagonistas na luta por um novo projeto de sustentabilidade local, baseado na equidade, participação e justiça social.

\section{Referências}

ACSERALD, H.; MELLO, C.C. A. O que é Justiça Ambiental. Rio de Janeiro: Garamond, 2009.

ARROYO, M. G. Currículo, Território em Disputa. Petrópolis: Vozes, 2011.

BOGDAN, R. C.; BIKLEN, S. K. Investigação Qualitativa em Educação. Uma Introdução à Teoria e aos Métodos. Portugal: Porto Editora, 1994.

BARDIN, L. Análise de Conteúdo. São Paulo: Edições 70, 2011.

BRASIL, Lei $n^{\circ} 11.482$, de 31 de maio de 2007.

BULLARD, R. Enfrentando o Racismo Ambiental no Século XXI. In ACSELRAD, H;HERCULANO, S.; PÁDUA, J. A. (Orgs.). Justiça Ambiental e Cidadania. Rio de Janeiro: Relume Dumará/Fundação Ford, p. 41-68, 2004.

COSENZA, A.; KASSIADOU, A.; SÁNCHEZ, C. Educação Ambiental e Direitos Humanos: necessárias articulações a partir da justiça ambiental e da ecologia política. In: SILVA, A. M. M. S.; TIRIBA, L. (Orgs.). Direito ao Ambiente como Direito à Vida: desafios para a educação em direitos humanos. São Paulo: Cortez,,p. 21-46, 2014.

COSENZA, A.; MARTINS, I. Controvérsias socioambientais no contexto da construção de sentidos sobre relações entre energia e ambiente na escola. Rev. Bras. Pesq. Educ. em Ciências, Belo Horizonte. v. 13, n.3, p. 73-94, 2013.

COSENZA, A.;MARTINS, I. Os sentidos de "conflito ambiental" na educação ambiental: uma análise dos periódicos de educação ambiental. Revista Ensino, Saúde e Ambiente, Niterói,v.2, n. 2, p. 234-245, Ago. 2012.

FURTADO, A. Obras da BR 440 continuam sem licenciamento.Acessa.com, Juiz de Fora, 20 abril 2010. Disponível em: <http://www.acessa.com/>. Acesso em: 12 fev. 2015. 
HALUZA-DELAY, R. Educating for Environmental Justice. International Journal of Science Education, v. 28, n. 10, p. 1201-1224, 2013.

LEVINSON, R. Towards a theoretical framework for teaching controversial socioscientific issues. International Journal of Science Education, v. 28, n10, p. 1201-1224, 2006.

LOUREIRO, C. Trajetória e fundamentos da educação ambiental. São Paulo: Cortez, 2004.

LOUREIRO, C. F. B.; LAYRARGUES, P. P. Ecologia política, justiça e educação ambiental crítica: perspectivas de aliança contra-hegemônica. Trab. Educ. Saúde, Rio de Janeiro, v. $11 \mathrm{n}$. 1, p. 53-71, Jan./Abr. 2013.

LOUREIRO, C. F. B.; TORRES, J. R. (orgs.). Educação ambiental: dialogando com Paulo Freire. São Paulo: Cortez, 2014.

MACEDO, J. A. B. Química Ambiental/ Uma Ciência ao Alcance. Belo Horizonte: Edição CRQ-MG, 2011.

PROJETO MEIO AMBIENTE E ALIMENTAÇÃO, Juiz de Fora, MG: Escola da Lagoa, s.p., 2013.

PROJETO MEIO AMBIENTE: ALIMENTAÇÃO, ESPORTE, CONSUMO E SUSTENTABILIDADE, Juiz de Fora, MG: Escola da Lagoa, s.p., 2014

ROCHA, C. H. B. Dos impactos sociais e ambientais do traçado da BR440 entre a BR040 (Vina Del Mar) e a BR267 (Jardim Esperança) com reflexos na MG353 (Grama). In: NÚCLEO DE ANÁLISE GEO-AMBIENTAL DA UFJF, Juiz de Fora, 2010. Disponível em: $<$ http://www.ufjf.br/analiseambiental/files/2010/12/1-Impactos-sociais-e-ambientais-

BR440.pdf >. Acesso em: 15 dez. 2015.

SCHLOSBERG, D. Defining Environmental Justice: Theories, Movements, and Nature. Oxford: Oxford University Press Inc., 2007.

VALENTE, E. Laudo questiona falta de licença ambiental da BR-440. Tribuna de Minas, Juiz de Fora, 13 dez. 2015. Disponível em: <http://www.tribunademinas.com.br/>. Acesso em: 13 dez. 2015.

VILARDI, L. G. A.; VILARDI, L. O. Práticas sociais e conflito ambiental: o caso da BR440.In: VII FÓRUM BRASILEIRO DE EDUCAÇÃO AMBIENTAL, Salvador, BA, s.p, 2012. 